\title{
Lateral cephalometric analysis of the nasal morphology among Saudi adults
}

This article was published in the following Dove Medical Press journal:

Clinical, Cosmetic and Investigational Dentistry

\author{
Aljazi Hussain Aljabaa \\ Division of Orthodontics, Department \\ of Pediatric Dentistry and \\ Orthodontics, College of Dentistry, \\ King Saud University, Riyadh, Saudi \\ Arabia
}

Purpose: This study was designed to establish normal values for the nasal form and its relationship to the other cranial structures among male and female skeletal class I Saudi adults. The results of males and females were compared to each other and to the results of a previous study using the same analysis method.

Patients and methods: Sixty-two lateral cephalometric radiographs of Saudi subjects (32 females and 30 males) were retrospectively retrieved from the orthodontic clinical data. Their ages ranged from 20 to 24 years old. All of the cephalometric radiographs were traced manually.

Results: There were statistically significant differences between the Saudi males and females in the nasal length, nasolabial angle, horizontal distance from the nose tip to the incisal edge of the most prominent upper central incisor, and chin. The Saudi males had longer dorsa and increased vertical distances from the pronasale to the chin when compared to the females. The Saudi females had longer vertical distances from the pronasale to the upper lip and larger nasolabial angles when compared to the males. The Saudi males and females had longer noses, longer dorsa, more curved noses (larger supratip break angles), and increased horizontal distances between the nose tip and the chin when compared to a New Zealand sample. The New Zealand sample had increased nasolabial angles, increased nasal tip projection angles, noses significantly projected from the upper lip, the most prominent central incisors, and more prominent maxillae when compared to the Saudi sample.

Conclusion: There were significant differences between the Saudi males and females, as well as between the Saudi sample and the New Zealand sample. These results suggest that both gender and ethnicity must be taken into account when establishing normal values for the nasal form and its relationship to the other cranial structures.

Keywords: lateral cephalometry, nasal analysis, orthodontics, rhinoplasty

\section{Introduction}

A harmonious balance between the different parts of the face is important when considering facial beauty, and the nose plays an important role in this balance due to its location in the middle of the face. ${ }^{1}$ In 1993, Czarnecki et al reported that the form of the nose and its relationship to the other parts of the face influence the perceptions of and attitudes toward the facial appearance. ${ }^{2}$ Consequently, patient assessment before an orthodontic treatment, orthognathic surgery, or rhinoplasty should involve a nasal form evaluation and an evaluation of its position with regard to the other facial structures. ${ }^{3}$

Several treatment types have direct or indirect effects on the nasal form, and thus, they can affect the facial appearance. Rhinoplasties and maxillary surgeries affect the
Correspondence: Aljazi Hussain Aljabaa Division of Orthodontics, Department of Pediatric Dentistry and Orthodontics, College of Dentistry, King Saud University, 8357 al buhayrat-ar rahmaniyah, Riyadh I2343-3664, Saudi Arabia

Email dr_aljazi@hotmail.com 
nasal form directly, ${ }^{4-10}$ while certain orthodontic treatments have indirect effects. For example, the retraction of protruding teeth will retrude the lips and increase the nasal prominence. ${ }^{11}$

Different methods have been used to evaluate the nose, including direct clinical measurements (morphometry), ${ }^{12}$ photogrammetry, ${ }^{13-15}$ radiography (cephalometry), ${ }^{3,16}$ and three-dimensional stereophotogrammetric imaging. ${ }^{17,18}$ Cephalometry has an advantage over morphometry and photogrammetry in that it provides imaging of the hard and soft tissue structures of the face. ${ }^{3}$ When compared to cone beam computed tomography, cephalometry is more cost effective, and it is used routinely in orthodontic patients. ${ }^{19}$

Previous studies have used different measurements and landmarks on lateral cephalometric radiographs in order to describe the form of the nose. In 1975, Wisth related the tip of the nose to both the hard and soft tissues by using conventional angular and linear measurements. ${ }^{20}$ Genecov et al measured the horizontal distances between the pronasale and a number of facial structures. ${ }^{21}$ In their study, Begg and Harkness used a quantitative method to evaluate the nasal form and its relationship to the other facial structures among Caucasian dental students. ${ }^{3}$ Moreover, Stark and Epker used a comprehensive method with different angular and horizontal measurements among American males and females. ${ }^{16}$

The aim of the present study was to establish normal values for the nasal form and its relationship to the other cranial structures among male and female skeletal class I adults using lateral cephalometric radiography. Then, comparison of the males and females results and the results of a previous study using the same method of analysis was done.

\section{Materials and methods}

This study was conducted in the Pediatric Dentistry and Orthodontics Department of the College of Dentistry at King Saud University in Riyadh, Saudi Arabia. Sixty-two lateral cephalometric radiographs of Saudi subjects (32 females and 30 males) were retrospectively retrieved from the orthodontic clinical data. The study protocol was approved by the Institutional Review Board (18/0597/IRB), King Saud University, College of Medicine, Riyadh, Saudi Arabia, and the College of Dentistry Research Centre (CDRC) at King Saud University (FR 0454). The present study was conducted in accordance with the declaration of Helsinki regarding human experimentation adopted in 1964 and revised in 2013. Patient consent was waived by the IRB as the data were previously recorded as routine practice and patients' data were handled with strict privacy and security throughout the study duration and publication.
Their ages ranged from 20 to 24 years old, and they were selected according to the following criteria: pleasant facial profile, class I molar and canine relationship, normal overjet and overbite, no crowding, competent lips, no previous orthodontic treatment, no previous rhinoplasty, no previous orthognathic treatment, no significant medical history, no trauma history, and no craniofacial deformities. All of the lateral cephalometric radiographs were taken while the teeth were in the intercuspal position with the lips at rest and the head in a natural position, as indicated by both the ear rods and the head supporting device.

All of the cephalometric radiographs were traced manually by the author (AA) on acetate paper using a $0.05 \mathrm{~mm}$ lead pencil. The tracing was performed in a dark room using a radiograph light source. Descriptions of the cephalometric reference points and planes follow. ${ }^{3,23-26}$ The angular and linear measurements, which were used in a previous study by Begg and Harkeness, ${ }^{3}$ are shown in Table 1 and Figures 1 and 2.

\section{Reference points and planes}

- $\mathrm{Cm}$ : columella point, the most anterior point on the columella of the nose. ${ }^{24}$

- DNP: dorsal nose plane, constructed by laying a straight edge on the upper aspect of the nose. ${ }^{11}$

- HP: horizontal reference plane, constructed by drawing a line through the soft tissue nasion parallel to the line through the nasion 7 degrees up from the sella-nasion line. ${ }^{3,24}$

- IS: incision superius, the incisal edge of the most prominent maxillary central incisor. ${ }^{25}$

- Ls: labrale superius, the most anterior point on the upper lip. ${ }^{24}$

- $\mathrm{N}$ : nasion, the most anterior point of the nasofrontal suture in the midsagittal plane. ${ }^{25}$

- PRN: pronasale, the most anterior point on the nose. ${ }^{23}$

- S: sella, the center of the pituitary fossa. ${ }^{25}$

- STG: soft tissue glabella, the most prominent point in the midsagittal plane of the forehead. ${ }^{24}$

- STN: soft tissue nasion, the point of greatest concavity in the soft tissue profile between the glabella and pronasale. ${ }^{23}$

- STPg: soft tissue pogonion, the most anterior point on the soft tissue of the chin. ${ }^{24}$

- Sn: subnasale, the point at which the nasal septum merges with the upper cutaneous lip in the midsagittal plane. ${ }^{24}$

- STP: supratip plane, the tangent to the supratip of the nose. $^{22}$

- VP: vertical plane, the perpendicular to the horizontal plane through the soft tissue nasion. ${ }^{3}$ 
Table I Angular and linear measurements

\begin{tabular}{|c|c|}
\hline \multicolumn{2}{|l|}{ Nasal measurements } \\
\hline STN-Sn & Nasal height ${ }^{26}$ \\
\hline STN-PRN & Nasal length ${ }^{20,27}$ \\
\hline PRN-VP & Nasal depth ${ }^{3}$ \\
\hline \multicolumn{2}{|l|}{ Nasal shape } \\
\hline STG-STN-DNP & Nasofrontal angle, the angle formed by the line from glabella through soft tissue nasion and the dorsal nose plane ${ }^{28}$ \\
\hline STP-DNP & Supratip break angle, measured from the dorsal nose plane to the supratip plane ${ }^{28}$ \\
\hline Cm-Sn-Ls & Nasolabial angle ${ }^{24}$ \\
\hline \multicolumn{2}{|c|}{ Position relative to other craniofacial structures (angles) } \\
\hline HP-DNP & Nasal projection angle, the internal angle between the horizontal plane and the dorsal nose plane ${ }^{22}$ \\
\hline STG-STPg-DNP & Nasofacial angle, the internal angle between the STG-STPg line and the dorsal nose plane ${ }^{28}$ \\
\hline DNP-PRN-SPg & $\begin{array}{l}\text { Nasomental angle, the internal angle formed by the dorsal nose plane and the line from pronasale to soft tissue } \\
\text { pogonion }^{28}\end{array}$ \\
\hline \multicolumn{2}{|c|}{ Linear measurements } \\
\hline PRN-Ls horizontal & Horizontal distance between PRN and Ls parallel to $\mathrm{HP}^{21}$ \\
\hline PRN-Is horizontal & Horizontal distance between PRN and Is parallel to $\mathrm{HP}^{3}$ \\
\hline PRN-STPg horizontal & Horizontal distance between PRN and STPg parallel to $\mathrm{HP}^{3}$ \\
\hline PRN-Ls vertical & Vertical distance between PRN and Ls measured parallel to VP3 \\
\hline PRN-Is vertical & Vertical distance between PRN and STPg measured parallel to VP³ \\
\hline PRN-STPg vertical & Vertical distance between PRN and STPg measured parallel to VP³ \\
\hline \multicolumn{2}{|c|}{ Relative prominence of maxilla and mandible } \\
\hline Sn-VP & Maxillary prominence, the distance between $\mathrm{Sn}$ and the vertical reference plane, measured parallel to $\mathrm{HP}^{3}$ \\
\hline STPg-VP & Mandibular prominence, the distance between STPg and the vertical reference plane, measured parallel to $\mathrm{HP}^{3}$ \\
\hline
\end{tabular}

Notes: STN: soft tissue nasion, the point of greatest concavity in the soft tissue profile between the glabella and pronasale. Sn: subnasale, the point at which the nasal septum merges with the upper cutaneous lip in the midsagittal plane. PRN: pronasale, the most anterior point on the nose. VP: vertical plane, the perpendicular to the horizontal plane through the soft tissue nasion. STG: soft tissue glabella, the most prominent point in the midsagittal plane of the forehead. DNP: dorsal nose plane, constructed by laying a straight edge on the upper aspect of the nose. STP: supratip plane, the tangent to the supratip of the nose. Cm: columella point, the most anterior point on the columella of the nose. Ls: labrale superius, the most anterior point on the upper lip. HP: horizontal reference plane, constructed by drawing a line through the soft tissue nasion parallel to the line through the nasion 7 degrees up from the sella-nasion line. STPg: soft tissue pogonion, the most anterior point on the soft tissue of the chin. Is: incision superius, the incisal edge of the most prominent maxillary central incisor.

\section{Data analysis}

For intraexaminer reliability, 20 radiographs were randomly selected and traced twice. Each time, the mean and SD of the measurement were calculated. Then, the Dahlberg error was calculated for each cephalometric measurement using the following formula:

$\sqrt{ }\left[\Sigma_{\mathrm{i}}\left(\text { first measurement }_{\mathrm{i}}-\text { second measurement }_{\mathrm{i}}\right)^{2} / 2 \mathrm{~N}\right]$, where $\mathrm{i}=$ observation and $\mathrm{N}=20$.

This type of error is commonly used to assess measurement errors in cephalometric studies. ${ }^{29-31}$ A paired $t$-test was used to investigate whether there was a significant difference between the first and second measurements.

The mean and SD were also estimated for both the males and females in the entire sample. To compare these estimates between the males and females, an independent samples $t$-test was used. Finally, the cephalometric measurement means were compared to the results from a New Zealand study conducted by Begg and Harkness ${ }^{3}$ using an independent samples $t$-test. All of the analyses were conducted using SAS 9.2 (SAS Institute Inc., Cary, NC, USA). A $P$-value of less than 0.05 was considered to be statistically significant.

\section{Results}

Table 2 shows the method error using Dahlberg's formula, and the least accurate measurements were the nasolabial angle, nasofrontal angle, and the three vertical linear nasal measurements. The most accurate measurements were the distance between the PRN and the STPg parallel to the HP, the nasofacial angle, nasal height, and supratip break angle. No significant differences were found between the first and second measurements.

A comparison was made between the Saudi males and females (Table 3), and there was a statistically significant difference in the nasal length (STN-PRN); the males had longer dorsa when compared to the females. In the nasolabial angle (Cm-Sn-Ls), the females had larger nasolabial angles when compared to the males. With regard to the nasal position in relation to the other craniofacial structures, there were statistically significant differences between the males and females in the horizontal distances relating the tip of the nose to the incisal edge of the most prominent upper central incisor (PRN-Is) and chin (PRN-STPg). Additionally, there were statistically significant differences in the vertical distances relating the tip of the nose to the upper lip 


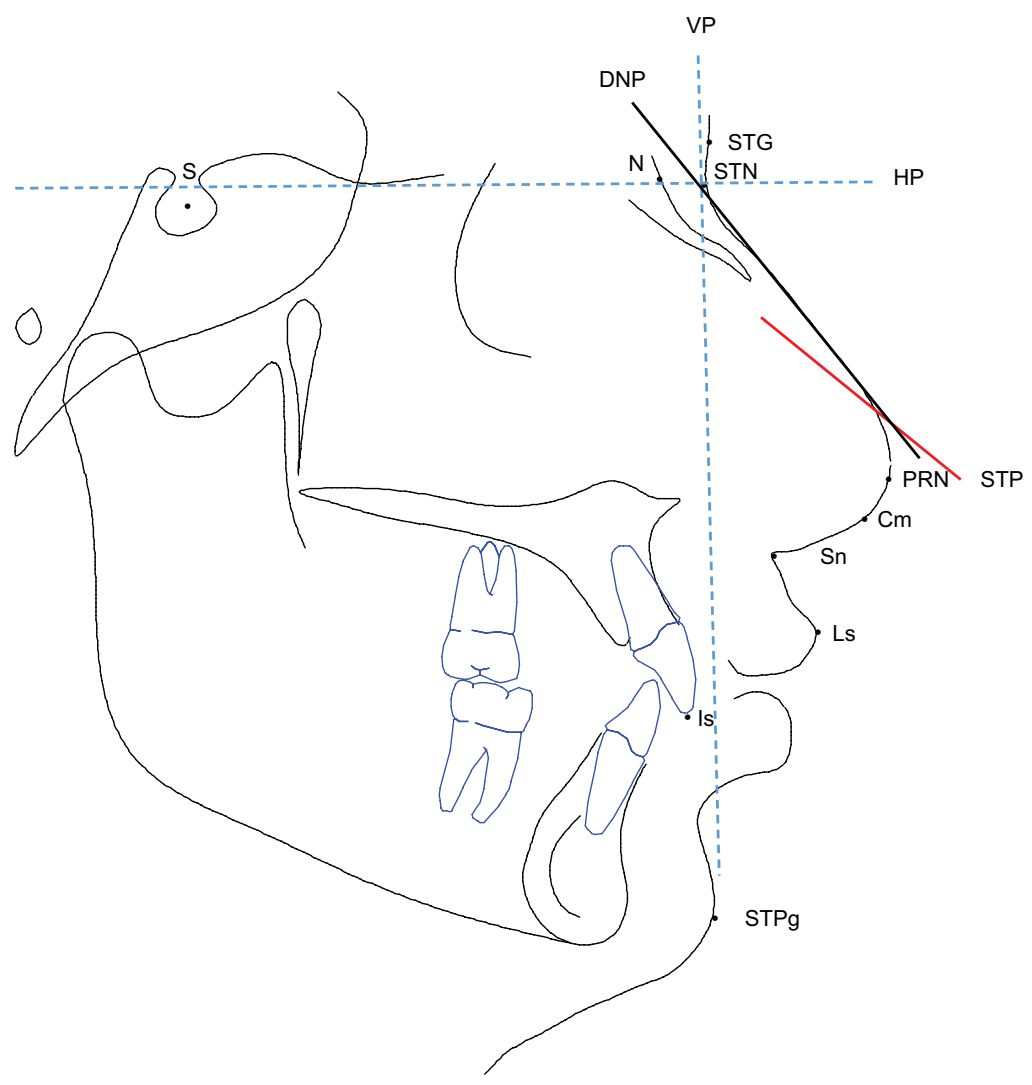

Figure I Reference points and planes.

Notes: STN: soft tissue nasion, the point of greatest concavity in the soft tissue profile between the glabella and pronasale. S: sella, the center of the pituitary fossa. N: nasion, the most anterior point of the nasofrontal suture in the midsagittal plane. Sn: subnasale, the point at which the nasal septum merges with the upper cutaneous lip in the midsagittal plane. PRN: pronasale, the most anterior point on the nose. VP: vertical plane, the perpendicular to the horizontal plane through the soft tissue nasion. STG: soft tissue glabella, the most prominent point in the midsagittal plane of the forehead. DNP: dorsal nose plane, constructed by laying a straight edge on the upper aspect of the nose. STP: supratip plane, the tangent to the supratip of the nose. Cm: columella point, the most anterior point on the columella of the nose. Ls: labrale superius, the most anterior point on the upper lip. HP: horizontal reference plane, constructed by drawing a line through the soft tissue nasion parallel to the line through the nasion 7 degrees up from the sella-nasion line. STPg: soft tissue pogonion, the most anterior point on the soft tissue of the chin. Is: incision superius, the incisal edge of the most prominent maxillary central incisor. The red line is the STP and the black line is the DNP.

(PRN-Ls) and chin (PRN-STPg). The male noses projected significantly further from the incisal edge of the maxillary central incisor and the chin when compared to the females, while the females had nose tips that were more projected from the upper lip.

Tables 4 and 5 demonstrate the comparisons for the mean measurements of the Saudi females and males in our study to the mean measurements of females and males reported in the New Zealand study, ${ }^{3}$ respectively. There were statistically significant differences between the Saudi sample and the New Zealand sample in several measurements. The Saudi males and females had longer noses (STN-Sn), longer dorsa (STN-PRN), more curved noses (reflected by larger supratip break angles), and increased horizontal distances between the tip of the nose and the chin. The New Zealand females and males had increased nasolabial angles, increased nasal tip projection angles, noses significantly projected from the upper lip, the most prominent central incisors, and more prominent maxillae when compared to the Saudi sample. In addition to the previously described measurements, the only measurement that was statistically different between the male samples was the nasal depth; the New Zealand males had deeper noses when compared to the Saudi males.

\section{Discussion}

Improving a patient's soft tissue profile is important when planning orthodontic treatment. Since the nose can be affected during orthodontic treatment, the nasal norms must be defined for each population. Starck and Epker conducted a nasal profile analysis of Caucasian American men and women, but their findings cannot be applied to other races. ${ }^{16}$ Other previous studies have investigated the soft tissue profiles and nasal profiles of different populations. ${ }^{3,31-33} \mathrm{In}$ Saudi Arabia, one study was conducted to determine the soft tissue norms, while two other studies measured the norms using the Holdaway analysis. However, there have 


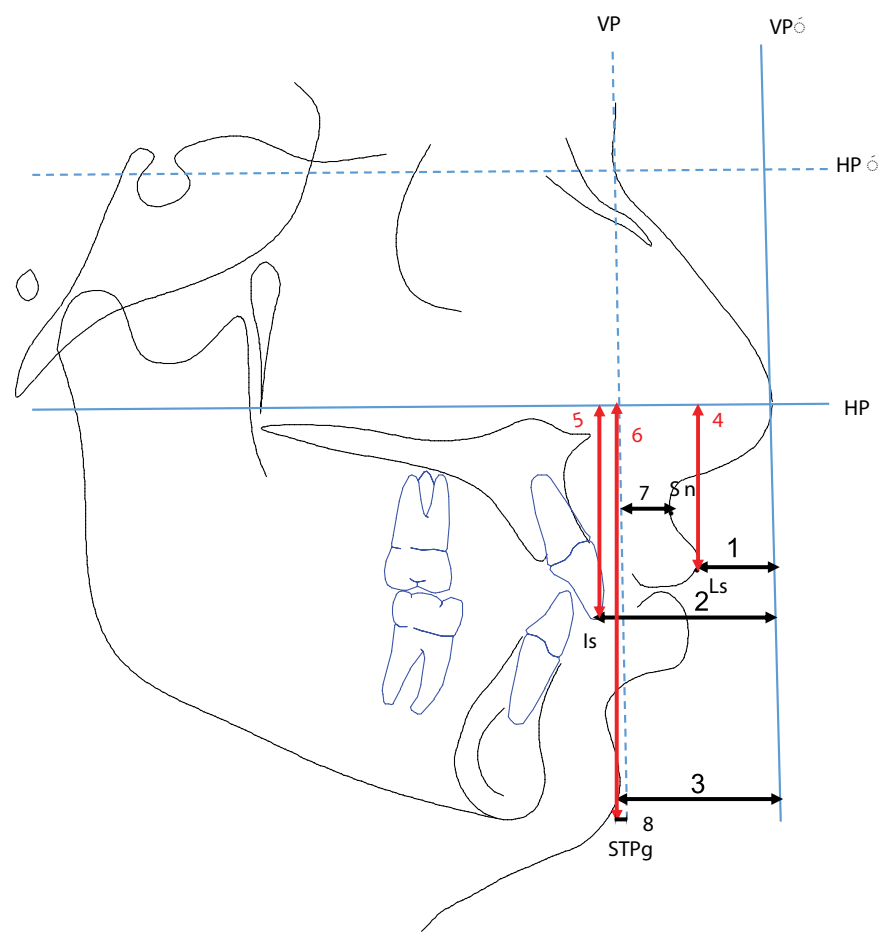

Figure 2 Horizontal and vertical measurements.

Notes: Sn: subnasale, the point at which the nasal septum merges with the upper cutaneous lip in the midsagittal plane.VP: vertical plane, the perpendicular to the horizontal plane through the soft tissue nasion. Ls: labrale superius, the most anterior point on the upper lip. HP: horizontal reference plane, constructed by drawing a line through the soft tissue nasion parallel to the line through the nasion 7 degrees up from the sella-nasion line. STPg: soft tissue pogonion, the most anterior point on the soft tissue of the chin. Is: incision superius, the incisal edge of the most prominent maxillary central incisor. IPRN-Ls horizontal, 2PRN-Is horizontal, 3PRN-STPg horizontal, 4PRN-Ls vertical, 5PRN-Is vertical, 6PRN-STPg vertical, 7Sn-VP, 8STPg-VP.

Table 2 Comparing repeated cephalometric measurements and estimating measurement error in a random sample of 20 participants, using Dahlberg's formula

\begin{tabular}{|c|c|c|c|c|c|}
\hline \multirow[t]{2}{*}{ Cephalometric measurement } & \multicolumn{2}{|c|}{$\begin{array}{l}\text { First } \\
\text { measurement }\end{array}$} & \multicolumn{2}{|c|}{$\begin{array}{l}\text { Second } \\
\text { measurement }\end{array}$} & \multirow[t]{2}{*}{$\begin{array}{l}\text { Dahlberg's } \\
\text { error }\end{array}$} \\
\hline & Mean & SD & Mean & SD & \\
\hline \multicolumn{6}{|l|}{ Nasal size measurements (mm) } \\
\hline Nasal height & 61.40 & 3.38 & 61.47 & 3.41 & 0.12 \\
\hline Nasal length & 55.30 & 4.69 & 55.30 & 4.77 & 0.15 \\
\hline Nasal depth & 22.33 & 2.79 & 22.35 & 2.74 & 0.21 \\
\hline \multicolumn{6}{|l|}{ Nasal shape measurements $\left({ }^{\circ}\right)$} \\
\hline Nasofrontal angle & 135.40 & 5.72 & 135.75 & 5.90 & 0.43 \\
\hline Supratip break angle & 13.10 & 2.22 & 13.08 & 2.22 & 0.13 \\
\hline Nasolabial angle & 101.45 & 13.93 & 102.05 & 13.87 & 0.60 \\
\hline \multicolumn{6}{|c|}{ Nasal position relative to other craniofacial structures } \\
\hline \multicolumn{6}{|c|}{ Angles $\left({ }^{\circ}\right)$} \\
\hline Nasal tip projection angle & 122.00 & 4.58 & 122.18 & 4.49 & 0.21 \\
\hline Nasofacial angle & 36.98 & 3.80 & 37.00 & 3.83 & 0.09 \\
\hline Nasomental angle & 122.10 & 6.74 & 122.22 & 6.81 & 0.20 \\
\hline \multicolumn{6}{|l|}{ Horizontal linear nasal measurements (mm) } \\
\hline Distance between PRN and Ls parallel to HP & 17.80 & 4.06 & 17.90 & 4.12 & 0.18 \\
\hline Distance between PRN and Is parallel to HP & 33.90 & 5.15 & 34.03 & 5.14 & 0.14 \\
\hline Distance between PRN and STPg parallel to HP & 30.80 & 5.62 & 30.83 & 5.58 & 0.07 \\
\hline \multicolumn{6}{|l|}{ Vertical linear nasal measurements $(\mathrm{mm})$} \\
\hline Distance between PRN and Ls parallel to VP & 23.85 & 3.75 & 24.12 & 3.70 & 0.35 \\
\hline Distance between PRN and Is parallel to VP & 33.00 & 2.88 & 33.31 & 2.72 & 0.43 \\
\hline Distance between PRN and STPg parallel to VP & 67.75 & 4.66 & 68.11 & 4.64 & 0.37 \\
\hline \multicolumn{6}{|l|}{ Prominence of maxilla and mandible $(\mathrm{mm})$} \\
\hline Maxilla & 3.48 & 2.84 & 3.59 & 2.82 & 0.17 \\
\hline Mandible & 8.05 & 6.09 & 8.12 & 6.05 & 0.22 \\
\hline
\end{tabular}

Notes: PRN: pronasale, the most anterior point on the nose. Ls: labrale superius, the most anterior point on the upper lip. HP: horizontal reference plane, constructed by drawing a line through the soft tissue nasion parallel to the line through the nasion 7 degrees up from the sella-nasion line. Is: incision superius, the incisal edge of the most prominent maxillary central incisor. STPg: soft tissue pogonion, the most anterior point on the soft tissue of the chin. VP: vertical plane, the perpendicular to the horizontal plane through the soft tissue nasion. 
Table 3 Comparing mean cephalometric measurements between males and females

\begin{tabular}{|c|c|c|c|c|c|}
\hline \multirow[t]{2}{*}{ Cephalometric measurement } & \multicolumn{2}{|c|}{ Males, $\mathbf{N}=\mathbf{3 0}$} & \multicolumn{2}{|c|}{ Females, $\mathbf{N}=\mathbf{3 0}$} & \multirow{2}{*}{$\begin{array}{l}t \text {-test } \\
P \text {-value }\end{array}$} \\
\hline & Mean & SD & Mean & SD & \\
\hline \multicolumn{6}{|l|}{ Nasal size measurements (mm) } \\
\hline Nasal height & 62.60 & 5.56 & 60.38 & 4.51 & 0.090 \\
\hline Nasal length & 58.60 & 4.34 & 53.00 & 3.25 & $0.000^{\mathrm{a}}$ \\
\hline Nasal depth & 24.50 & 4.84 & 22.98 & 4.64 & 0.214 \\
\hline \multicolumn{6}{|l|}{ Nasal shape measurements $\left({ }^{\circ}\right)$} \\
\hline Nasofrontal angle & 134.67 & 7.58 & 137.33 & 6.48 & 0.144 \\
\hline Supratip break angle & 13.28 & 2.07 & 13.16 & 2.17 & 0.814 \\
\hline Nasolabial angle & 96.23 & 12.74 & 104.19 & 11.92 & $0.014^{b}$ \\
\hline \multicolumn{6}{|c|}{ Nasal position relative to other craniofacial structures } \\
\hline \multicolumn{6}{|c|}{ Angles $\left({ }^{\circ}\right)$} \\
\hline Nasal tip projection angle & 123.60 & 5.81 & 122.80 & 4.93 & 0.561 \\
\hline Nasofacial angle & 37.53 & 4.34 & 36.34 & 3.29 & 0.232 \\
\hline Nasomental angle & 121.78 & 5.04 & 123.44 & 6.14 & 0.250 \\
\hline \multicolumn{6}{|l|}{ Horizontal linear nasal measurements $(\mathrm{mm})$} \\
\hline Distance between PRN and Ls parallel to HP & 17.63 & 4.04 & 16.44 & 3.95 & 0.244 \\
\hline Distance between PRN and Is parallel to HP & 33.87 & 4.77 & 30.31 & 3.91 & $0.002^{\mathrm{a}}$ \\
\hline Distance between PRN and STPg parallel to HP & 31.88 & 5.34 & 28.47 & 4.93 & $0.01 \mathrm{I}^{\mathrm{b}}$ \\
\hline \multicolumn{6}{|l|}{ Vertical linear nasal measurements $(\mathrm{mm})$} \\
\hline Distance between PRN and Ls parallel to VP & 23.40 & 3.41 & 25.38 & 3.43 & 0.027 \\
\hline Distance between PRN and Is parallel to VP & 34.30 & 4.07 & 33.78 & 3.61 & 0.598 \\
\hline Distance between PRN and STPg parallel to VP & 72.27 & 6.07 & 64.92 & 11.58 & $0.003^{\mathrm{a}}$ \\
\hline \multicolumn{6}{|l|}{ Prominence of maxilla and mandible $(\mathrm{mm})$} \\
\hline Maxilla & 5.67 & 5.07 & 4.91 & 3.81 & 0.509 \\
\hline Mandible & 6.68 & 7.23 & 6.44 & 6.37 & 0.888 \\
\hline
\end{tabular}

Notes: ${ }^{a} P$-value for $t$-test comparing mean cephalometric measurement between males and females $<0.0 \mathrm{I}$. ${ }^{\mathrm{b}} \mathrm{P}$-value for $t$-test comparing mean cephalometric measurement between males and females $<0.05$. PRN: pronasale, the most anterior point on the nose. Ls: labrale superius, the most anterior point on the upper lip. HP: horizontal reference plane, constructed by drawing a line through the soft tissue nasion parallel to the line through the nasion 7 degrees up from the sella-nasion line. Is: incision superius, the incisal edge of the most prominent maxillary central incisor. STPg: soft tissue pogonion, the most anterior point on the soft tissue of the chin. VP: vertical plane, the perpendicular to the horizontal plane through the soft tissue nasion.

been no studies that concentrated on the nasal analysis in detail. ${ }^{34-36}$ For these reasons, this study was carried out on a basis similar to that used by Begg and Harkness; it combined the measurements used by others to evaluate the form and position of the nose in studies of nasal growth, before rhinoplasty, orthognathic surgery, and some forms of orthodontic treatment. ${ }^{3}$

The reproducibility of the soft tissue measurements can be affected by facial expressions, especially the mobile parts. ${ }^{37}$ The nasolabial angle, nasofrontal angle, vertical distance from the pronasale to the upper lip, most prominent central incisor, and chin were the least accurate measurements, which agreed with the findings of Begg and Harkness. ${ }^{3}$

In the current study, the nose was evaluated in terms of the nasal size, shape, and position in relation to the other craniofacial structures, as well as the relative prominences of the maxilla and mandible. The Saudi females and males' norms were measured, and these norms were compared to the New Zealanders' norms, which were found using the same analysis. ${ }^{3}$
Overall, the Saudi males had longer dorsa (STN-PRN) and increased vertical distances from the pronasale to the chin (PRN-STPg) when compared to the females, which was in agreement with the study by Begg and Harkness. ${ }^{3}$ However, the females had longer vertical distances from the pronasale to the upper lip when compared to the males, which was contradictory to the results of Begg and Harkenss, ${ }^{3}$ and this might be due to the difference in ethnicity. Moreover, it was noted that the Saudi females had larger nasolabial angles when compared to the males. When comparing the results of the current study with those of other studies done in Saudi Arabia, Hashim and AlBarakati measured the nasolabial angles of 56 Saudi males and females, and they found that the Saudi females had larger nasolabial angles, but their findings were not statistically significant. In addition, they measured the nasal depth, and their results were in agreement with those of the current study: no significant difference was found between the males and females with regard to the nasal depth. ${ }^{34}$ Albarakati and Bindayel measured the nose prominence using the Holdaway cephalometric analysis, and 
Table 4 Comparing mean cephalometric measurements among female populations in Saudi and New Zealand samples

\begin{tabular}{|c|c|c|c|c|c|}
\hline \multirow[t]{2}{*}{ Cephalometric measurement } & \multicolumn{2}{|c|}{ Saudi study, N=32 } & \multicolumn{2}{|c|}{$\begin{array}{l}\text { New Zealand } \\
\text { study } \\
\mathbf{N}=\mathbf{2 5}\end{array}$} & \multirow[t]{2}{*}{$\begin{array}{l}t \text {-test } \\
P \text {-value }\end{array}$} \\
\hline & Mean & SD & Mean & SD & \\
\hline \multicolumn{6}{|l|}{ Nasal size measurements (mm) } \\
\hline Nasal height & 60.38 & 4.51 & 53.66 & 3.80 & $0.000^{\mathrm{a}}$ \\
\hline Nasal length & 53.00 & 3.25 & 46.18 & 4.19 & $0.000^{\mathrm{a}}$ \\
\hline Nasal depth & 22.98 & 4.64 & 24.61 & 2.09 & 0.083 \\
\hline \multicolumn{6}{|l|}{ Nasal shape measurements $\left({ }^{\circ}\right)$} \\
\hline Nasofrontal angle & 137.33 & 6.48 & 135.13 & 5.06 & 0.156 \\
\hline Supratip break angle & 13.16 & 2.17 & 9.07 & 3.84 & $0.000^{\mathrm{a}}$ \\
\hline Nasolabial angle & 104.19 & 11.92 & 112.15 & 9.08 & $0.006^{\mathrm{a}}$ \\
\hline \multicolumn{6}{|l|}{ Nasal position relative to other craniofacial structures } \\
\hline \multicolumn{6}{|l|}{ Angles $\left({ }^{\circ}\right)$} \\
\hline Nasal tip projection angle & 122.80 & 4.93 & 127.78 & 4.92 & $0.000^{\mathrm{a}}$ \\
\hline Nasofacial angle & 36.34 & 3.29 & 38.04 & 3.43 & 0.065 \\
\hline Nasomental angle & 123.44 & 6.14 & 123.28 & 4.50 & 0.910 \\
\hline \multicolumn{6}{|l|}{ Horizontal linear nasal measurements (mm) } \\
\hline Distance between PRN and Ls parallel to HP (PRN-Ls) & 16.44 & 3.95 & 16.62 & 3.44 & 0.855 \\
\hline Distance between PRN and Is parallel to HP (PRN-Is) & 30.31 & 3.91 & 29.36 & 4.02 & 0.375 \\
\hline Distance between PRN and STPg parallel to HP & 28.47 & 4.93 & 22.94 & 7.65 & $0.003^{\mathrm{a}}$ \\
\hline \multicolumn{6}{|l|}{ Vertical linear nasal measurements $(\mathrm{mm})$} \\
\hline Distance between PRN and Ls parallel to VP (PRN-LsV) & 25.38 & 3.43 & 27.80 & 2.55 & $0.004^{\mathrm{a}}$ \\
\hline Distance between PRN and Is parallel to VP (PRN-IsVP) & 33.78 & 3.61 & 37.77 & 3.09 & $0.000^{\mathrm{a}}$ \\
\hline Distance between PRN and STPg parallel to VP & 64.92 & 11.58 & 64.56 & 4.13 & 0.871 \\
\hline \multicolumn{6}{|l|}{ Prominence of maxilla and mandible $(\mathbf{m m})$} \\
\hline Maxilla & 4.91 & 3.81 & 7.87 & 2.99 & $0.002^{\mathrm{a}}$ \\
\hline Mandible & 6.44 & 6.37 & 2.93 & 6.70 & 0.050 \\
\hline
\end{tabular}

Notes: a $P$-value for $t$-test comparing mean cephalometric measurement between males and females $<0.01$. ${ }^{b} P$-value for $t$-test comparing mean cephalometric measurement between males and females $<0.05$. PRN: pronasale, the most anterior point on the nose. Ls: labrale superius, the most anterior point on the upper lip. HP: horizontal reference plane, constructed by drawing a line through the soft tissue nasion parallel to the line through the nasion 7 degrees up from the sella-nasion line. Is: incision superius, the incisal edge of the most prominent maxillary central incisor. STPg: soft tissue pogonion, the most anterior point on the soft tissue of the chin. VP: vertical plane, the perpendicular to the horizontal plane through the soft tissue nasion.

they found that the males had more prominent noses when compared to the females; however, their findings cannot be compared to the findings of this study because they used another method of analysis. ${ }^{35}$ Another study also used the Holdaway analysis to measure the nasal prominence and length among 100 Saudi patients. No significant differences were found between the males and females in either the nasal length or nasal prominence, which contradicts the current results. This might be explained by the differences in the landmarks and the analyses used. Moreover, in that study, it was mentioned that the X-rays were traced by students, without stating whether an interexaminer reliability test was conducted. ${ }^{36}$

When comparing the results reported in the current study with the New Zealand sample, ${ }^{3}$ the Saudi males and females had longer noses (STN-Sn), longer dorsa (STN-PRN), larger supratip break angles, and increased horizontal distances between the tip of the nose and the chin. The New Zealand females and males had increased nasolabial angles, increased nasal tip projection angles, noses significantly projected from the upper lip, the most prominent central incisors, and more prominent maxillae when compared to the Saudi sample. These findings are due to the difference in ethnicity, which is to be expected.

The findings of the current study are in agreement with those of El-Hadidy et al, who investigated the nasal morphologies of 60 Egyptian males and females. They reported that the males had significantly longer vertical and horizontal measurements when compared to the females $(P<0.001)$. However, the females had more obtuse nasofrontal angles $\left(139^{\circ}\right)$ and nasolabial angles $(P<0.001)$ than the males. ${ }^{33}$

The value of the current study lies in the fact that it provides nasal norms that can be used as a reference during the diagnosis and treatment planning of patients undergoing orthodontic treatment, orthognathic surgery, and rhinoplasty, thus improving the posttreatment results. Future studies with larger samples of both genders should be considered. 
Table 5 Comparing mean cephalometric measurements among male populations in Saudi and New Zealand samples

\begin{tabular}{|c|c|c|c|c|c|}
\hline \multirow[t]{2}{*}{ Cephalometric measurement } & \multicolumn{2}{|c|}{ Saudi study, $N=30$} & \multicolumn{2}{|c|}{$\begin{array}{l}\text { New Zealand } \\
\text { study }^{3}, N=25\end{array}$} & \multirow[t]{2}{*}{$\begin{array}{l}t \text {-test } \\
P \text {-value }\end{array}$} \\
\hline & Mean & SD & Mean & SD & \\
\hline \multicolumn{6}{|l|}{ Nasal size measurements (mm) } \\
\hline Nasal height & 62.60 & 5.56 & 58.10 & 4.18 & $0.00 \mathrm{I}^{\mathrm{a}}$ \\
\hline Nasal length & 58.60 & 4.34 & 51.45 & 3.69 & $0.000^{\mathrm{a}}$ \\
\hline Nasal depth & 24.50 & 4.84 & 29.03 & 2.73 & $0.000^{\mathrm{a}}$ \\
\hline \multicolumn{6}{|l|}{ Nasal shape measurements $\left({ }^{\circ}\right)$} \\
\hline Nasofrontal angle & 134.67 & 7.58 & 133.92 & 6.89 & 0.703 \\
\hline Supratip break angle & 13.28 & 2.07 & 5.31 & 5.47 & $0.000^{\mathrm{a}}$ \\
\hline Nasolabial angle & 96.23 & 12.74 & 110.06 & 8.32 & $0.000^{\mathrm{a}}$ \\
\hline \multicolumn{6}{|l|}{ Nasal position relative to other craniofacial structures } \\
\hline \multicolumn{6}{|l|}{ Angles $\left({ }^{\circ}\right)$} \\
\hline Nasal tip projection angle & 123.60 & 5.81 & 129.64 & 3.92 & $0.000^{\mathrm{a}}$ \\
\hline Nasofacial angle & 37.53 & 4.34 & 38.37 & 2.92 & 0.398 \\
\hline Nasomental angle & 121.78 & 5.04 & 121.93 & 4.86 & 0.911 \\
\hline \multicolumn{6}{|l|}{ Horizontal linear nasal measurements $(\mathrm{mm})$} \\
\hline Distance between PRN and Ls parallel to HP (PRN-Ls) & 17.63 & 4.04 & 16.60 & 4.85 & 0.402 \\
\hline Distance between PRN and Is parallel to HP (PRN-Is) & 33.87 & 4.77 & 31.33 & $5.4 \mathrm{I}$ & 0.074 \\
\hline Distance between PRN and STPg parallel to HP & 31.88 & 5.34 & 24.38 & 7.29 & $0.000^{\mathrm{a}}$ \\
\hline \multicolumn{6}{|l|}{ Vertical linear nasal measurements $(\mathrm{mm})$} \\
\hline Distance between PRN and Ls parallel to VP (PRN-LsV) & 23.40 & 3.41 & 31.44 & 2.43 & $0.000^{\mathrm{a}}$ \\
\hline Distance between PRN and Is parallel to VP (PRN-IsVP) & 34.30 & 4.07 & 42.30 & 2.60 & $0.000^{\mathrm{a}}$ \\
\hline Distance between PRN and STPg parallel to VP & 72.27 & 6.07 & 72.19 & 5.72 & 0.960 \\
\hline \multicolumn{6}{|l|}{ Prominence of maxilla and mandible $(\mathrm{mm})$} \\
\hline Maxilla & 5.67 & 5.07 & 11.49 & 3.42 & $0.000^{\mathrm{a}}$ \\
\hline Mandible & 6.68 & 7.23 & 3.64 & 7.80 & 0.143 \\
\hline
\end{tabular}

Notes: ${ }^{a} P$-value for $t$-test comparing mean cephalometric measurement between males and females $<0.01$. ${ }^{b}$-value for $t$-test comparing mean cephalometric measurement between males and females $<0.05$. PRN: pronasale, the most anterior point on the nose. Ls: labrale superius, the most anterior point on the upper lip. HP: horizontal reference plane, constructed by drawing a line through the soft tissue nasion parallel to the line through the nasion 7 degrees up from the sella-nasion line. Is: incision superius, the incisal edge of the most prominent maxillary central incisor. STPg: soft tissue pogonion, the most anterior point on the soft tissue of the chin. VP: vertical plane, the perpendicular to the horizontal plane through the soft tissue nasion.

\section{Conclusion}

- The Saudi males had longer dorsa and increased vertical distances from the pronasale to the chin when compared to the females.

- The Saudi females had longer vertical distances from the pronasale to the upper lip and larger nasolabial angles when compared to the males.

- The Saudi sample had longer noses, longer dorsa, larger supratip break angles, and increased horizontal distances between the tip of the nose and the chin when compared to the New Zealand sample.

- The New Zealand sample had increased nasolabial angles, increased nasal tip projection angles, noses significantly projected from the upper lip, the most prominent central incisors, and more prominent maxillae when compared to the Saudi sample.

\section{Acknowledgments}

This research project was supported by a grant from the Research Center at the Center for Female Scientific and
Medical Colleges, Deanship of Scientific Research, King Saud University in Saudi Arabia.

\section{Disclosure}

The author reports no conflicts of interest in this work.

\section{References}

1. Gulsen A, Okay C, Aslan BI, Uner O, Yavuzer R. The relationship between craniofacial structures and the nose in Anatolian Turkish adults: a cephalometric evaluation. Am J Orthod Dentofacial Orthop. 2006;130(2):131.e15-131.e25.

2. Czarnecki ST, Nanda RS, Currier GF. Perceptions of a balanced facial profile. Am J Orthod Dentofacial Orthop. 1993;104(2):180-187.

3. Begg RJ, Harkness M. A lateral cephalometric analysis of the adult nose. J Oral Maxillofac Surg. 1995;53(11):1268-1274.

4. O'Ryan F, Schendel S. Nasal anatomy and maxillary surgery. I. Esthetic and anatomic principles. Int J Adult Orthodon Orthognath Surg. 1989;4(1):27-37.

5. Schendel SA, Carlotti AE Jr. Nasal considerations in orthognathic surgery. Am J Orthod Dentofacial Orthop. 1991;100(3):197-208.

6. Dann JJ 3rd, Fonseca RJ, Bell WH. Soft tissue changes associated with total maxillary advancement: a preliminary study. J Oral Surg. 1976;34(1):19-23.

7. Freihofer HP Jr. Changes in nasal profile after maxillary advancement in cleft and non-cleft patients. J Maxillofac Surg. 1977;5(1):20-27. 
8. Radney LJ, Jacobs JD. Soft-tissue changes associated with surgical total maxillary intrusion. Am J Orthod. 1981;80(2):191-212.

9. Kinnebrew MC, Emison JW. Simultaneous maxillary and nasal reconstruction. An analysis of twenty-five cases. J Craniomaxillofac Surg. 1987;15(6):312-325.

10. Waite PD, Matukas VJ. Indications for simultaneous orthognathic and septorhinoplastic surgery. J Oral Maxillofac Surg. 1991;49(2):133-140.

11. Robison JM, Rinchuse DJ, Zullo TG. Relationship of skeletal pattern and nasal form. Am J Orthod. 1986;89(6):499-506.

12. Zhang XT, Wang SK, Zhang W, Wang XF. Measurement and study of the nose and face and their correlations in the young adult of Han nationality. Plast Reconstr Surg. 1990;85(4):532-536.

13. Neger M. A quantitative method for the evaluation of the soft-tissue facial profile. Am J Orthod. 1959;45(10):738-751.

14. Fernández-Riveiro P, Smyth-Chamosa E, Suárez-Quintanilla D, SuárezCunqueiro M. Angular photogrammetric analysis of the soft tissue facial profile. Eur J Orthod. 2003;25(4):393-399.

15. Anić-Milosević S, Lapter-Varga M, Slaj M. Analysis of the soft tissue facial profile by means of angular measurements. Eur J Orthod. 2008;30(2):135-140.

16. Starck WJ, Epker BN. Cephalometric analysis of profile nasal esthetics. Part I. Method and normative data. Int J Adult Orthodon Orthognath Surg. 1996;11(2):91-103.

17. Dong Y, Zhao Y, Bai S, Wu G, Wang B. Three-dimensional anthropometric analysis of the Chinese nose. $J$ Plast Reconstr Aesthet Surg. 2010;63(11):1832-1839.

18. Cevidanes LH, Motta A, Proffit WR, Ackerman JL, Styner M. Cranial base superimposition for 3-dimensional evaluation of softtissue changes. Am J Orthod Dentofacial Orthop. 2010;137(4 Suppl): S120-S129.

19. Isiekwe GI, daCosta OO, Utomi IL, Sanu OO. Holdaway's analysis of the nose prominence of an adult Nigerian population. Niger J Clin Pract. 2015;18(4):548-552.

20. Wisth PJ. Nose morphology in individuals with Angle Class I, Class II or Class III occlusions. Acta Odontol Scand. 1975;33(1):197: 53-57.

21. Genecov JS, Sinclair PM, Dechow PC. Development of the nose and soft tissue profile. Angle Orthod. 1990;60(3):191-198.

22. Gassmann CJ, Nishioka GJ, Van Sickels JE, Thrash WJ. A lateral cephalometric analysis of nasal morphology following Le Fort I osteotomy applying photometric analysis techniques. J Oral Maxillofac Surg. 1989;47(9):926-930.
23. Mansour S, Burstone C, Legan H. An evaluation of soft-tissue changes resulting from Le Fort I maxillary surgery. Am J Orthod. 1983;84(1):37-47.

24. Legan HL, Burstone CJ. Soft tissue cephalometric analysis for orthognathic surgery. J Oral Surg. 1980;38(10):744-751.

25. Burstone CJ, James RB, Legan H, Murphy GA, Norton LA. Cephalometrics for orthognathic surgery. J Oral Surg. 1978;36(4):269-277.

26. Davenport CB. Postnatal development of the human outer nose. Proc Am Philos Sot. 1939;80:175-355.

27. Chaconas SJ. A statistical evaluation of nasal growth. Am J Orthod. 1969;56(4):403-414.

28. Powell N, Humphreys B. Proportions of the Aesthetic Face. New York, NY: Thieme-Stratton; 1984.

29. Kim HY. Statistical notes for clinical researchers: Evaluation of measurement error 2: Dahlberg's error, Bland-Altman method, and Kappa coefficient. Restor Dent Endod. 2013;38(3):182-185.

30. Dahlberg G. Statistical Methods for Medical and Biological Students. London: George Allen and Unwin; 1940:122-132.

31. Alcalde RE, Jinno T, Orsini MG, Sasaki A, Sugiyama RM, Matsumura T. Soft tissue cephalometric norms in Japanese adults. Am J Orthod Dentofacial Orthop. 2000;118(1):84-89.

32. Hwang HS, Kim WS, McNamara JA. A comparative study of two methods of quantifying the soft tissue profile. Angle Orthod. 2000;70(3):200-207.

33. El-Hadidy M, El-Din AB, El-Bassioni L, Attal W. Cephalometric analysis for evaluating the profile nasal morphology in Egyptian adults. Egypt J Plast Reconstr Surg. 2007;2:243-249.

34. Hashim HA, Albarakati SF. Cephalometric soft tissue profile analysis between two different ethnic groups: a comparative study. J Contemp Dent Pract. 2003;4(2):60-73.

35. Albarakati SF, Bindayel NA. Holdaway soft tissue cephalometric standards for Saudi adults. King Saud Univ J Dental Sci. 2012;3(1): 27-32.

36. Kundi I. Cephalometric soft tissue standard and gender dimorphism in nasal prominence estimated by Holdaway's analysis in patients visiting college of dentistry, Aljouf University. J Contemp Dent Pract. 2017;18(2):152-155.

37. Wisth PJ, Böe OE. The reliability of cephalometric soft tissue measurements. Arch Oral Biol. 1975;20(9):595-599.
Clinical, Cosmetic and Investigational Dentistry

\section{Publish your work in this journal}

Clinical, Cosmetic and Investigational Dentistry is an international, peer-reviewed, open access, online journal focusing on the latest clinical and experimental research in dentistry with specific emphasis on cosmetic interventions. Innovative developments in dental materials, techniques and devices that improve outcomes and patient satisfac-
Dovepress

tion and preference will be highlighted. The manuscript management system is completely online and includes a very quick and fair peerreview system, which is all easy to use. Visit http://www.dovepress com/testimonials.php to read real quotes from published authors. 